\title{
Production of Sexual Hybrid Progenies for Clarifying the Phylogenic Relationship between Citrus and Citropsis species
}

\author{
Masaki Yahata ${ }^{1}$ \\ The United Graduate School of Agricultural Sciences, Kagoshima University, 1-21-24 Korimoto, \\ Kagoshima-shi, Kagoshima 890-0065, Japan \\ Hisato Kunitake ${ }^{2}$, Kiichi Yasuda, and Kensuke Yamashita \\ Faculty of Agriculture, University of Miyazaki, 1-1 Gakuenkibanadainishi, Miyazaki-shi, Miyazaki \\ 889-2192, Japan \\ Haruki Komatsu \\ School of Agriculture, Kyushu Tokai University, Kawayo, Minamiaso-mura, Aso-gun, Kumamoto 869- \\ 1404, Japan \\ Ryoji Matsumoto \\ Faculty of Agriculture, Saga University, Honjyo-machi, Saga-shi, Saga 840-8502, Japan
}

AdDitional Index words. Aurantioideae, CAPS, Citropsis schweinfurthii, flow cytometry, RAPD, nuclear genome size

\begin{abstract}
The reciprocal crosses between two citrus cultivars and Citropsis schweinfurthii (Engl.) Swing. \& M. Kell. were conducted. The cross between 'Nanpu' tangor ('Kiyomi' tangor (Citrus unshiu Marc. $\mathrm{x} C$. sinensis Osbeck) $\mathrm{X}$ 'Fairchild' tangerine-tangelo [clementine (C. clementina hort. ex Tanaka) $x$ 'Orlando' tangelo ( $C$. paradisi Macf. $\times$ C reticulata Blanco)]\} and $C$. schweinfurthii produced some developed seeds with an average weight approximately $1 / 10$ of that of the seeds obtained from open pollination in 'Nanpu' tangor. These seeds germinated on Murashige and Tucker medium, and three and 28 seedlings were obtained from crosses using $C$. schweinfurthii as the female and the male parent, respectively. The absolute nuclear genome size of these seedlings [ $\sim 8.84 \mathrm{pg}$ of DNA content per somatic nucleus (2C)] was intermediate of that of the 'Nanpu' tangor $(0.78 \mathrm{pg} / 2 \mathrm{C})$ and $C$. schweinfurthii $(0.90 \mathrm{pg} / 2 \mathrm{C})$ seedlings. The chromosome counts of the young leaves revealed that they were diploids $(2 n=2 X=18)$. Furthermore, the hybridity of the seedlings obtained from the reciprocal crosses between 'Nanpu' tangor and $C$. schweinfurthii was confirmed by randomly amplified polymorphic DNA (RAPD) analysis and cleaved amplified polymorphic sequence (CAPS) analysis. These hybrids will be utilized as important materials for investigating the phylogenic relationships between these genera in the subfamily Aurantioideae.
\end{abstract}

In the family Rutaceae, the subfamily Aurantioideae (Citroideae) is an important group of plants, with many species of commercial importance inducing those belonging to two genera, Citrus L. and Fortunella Swing. Therefore, it is important to understand the phylogenetic relationships among the different taxa of this subfamily for further breeding, and for developing better conservation strategies. The most widely accepted classifications by Swingle and Reece (1967) and Tanaka (1977) are based on traditional taxonomic methods using morphology and anatomy. Recently, many studies have been carried out to clarify the phylogenic relationships among the Aurantioideae by using molecular markers such as isozymes, restriction fragment length polymorphisms (RFLPs) of chloroplasts ( $\mathrm{cp}$ ) and mitochondrial (mt) DNA, RAPD, and sequence-characterized amplified regions

Received for publication 28 Nov. 2005. Accepted for publication 25 June 2006. The authors are grateful to Dr. Masahiro Mii, Faculty of Horticulture, Chiba University, for his advice and critical reading of this manuscript. The authors thank Mr. Yasuhiro Okuno for kindly providing the experimental materials. This research was supported by Diet and Cancer Prevention: Exploring Research Technology, Miyazaki Prefecture Collaboration of Regional Entities for the Advancement of Technological Excellence, JST, and the Sasakawa Scientific Research Grant from The Japan Science Society. ${ }^{1}$ Current address: Faculty of Agriculture, Shizuoka University, 836 Ohya, Shizuoka-shi, Shizuoka 422-8529, Japan.

${ }^{2}$ Corresponding author; e-mail address: hkuni@cc.miyazaki-u.ac.jp
(SCARs) (Federici et al., 1998; Green et al., 1986; Hirai and Kajiura, 1987; Hirai et al., 1986; Nicolosi et al., 2000; Yamamoto and Kobayashi, 1996; Yamamoto et al., 1993). However, clear information on the origin of Citrus has not been obtained from these studies.

Citropsis (Engl.) Swing. \& M. Kell. species, native to Africa, are considered to be a surviving form of the remote ancestors of Citrus because the leaflets, especially the unifoliate leaves of certain forms of $C$. schweinfurthi, very closely resemble those of Citrus in shape, texture, venation, and color (Swingle and Reece, 1967). Therefore, the production of intergeneric hybrids between Citrus and Citropsis has been attempted to clarify their relationship (Barrett, 1977; Iwamasa et al., 1985, 1988). So far, somatic hybrids have been produced in several combinations of Citrus and Citropsis [e.g., 'Hamlin' sweet orange (C. sinensis) + Citropsis gilletiana Swing. \& M. Kell. (Grosser and Gmitter, 1990), 'Cleopatra' mandarin $(C$. reticulata $)+C$. gilletiana (Grosser et al., 1990), Ponkan (C. reticulata) + Citropsis gabunensis $($ Engl. $)$ Swing. \& M. Kell. (Ling and Iwamasa, 1994), 'Succari' sweet orange (C. sinensis) + C. gilletiana (Grosser et al., 1996), and 'Shogun' mandarin $(C$. reticulata $)+C$. gabunensis (Takami et al., 2005)].

Intergeneric crosses between Citrus and Citropsis have also been attempted (Barrett, 1977; Iwamasa etal., 1988). Barrett(1977) 
obtained developed seeds from the cross of $C$. schweinfurthii with Citrus medica L. Iwamasa et al. (1988) confirmed that when some monoembryonic citrus cultivars were pollinated with pollen of C. schweinfurthii, the Citropsis pollen tube reached very near the micropyle of the citrus ovule after intergeneric pollination, and several developed and undeveloped seeds were obtained. However, in these reports there was no germination from seeds obtained from these crosses, and hybrid seedlings have not yet been obtained from the crosses between Citrus and Citropsis.

We report here the production of intergeneric sexual hybrids from the reciprocal crosses between the citrus cultivar and $C$. schweinfurthii.

\section{Materials and Methods}

Plant materials and the Reciprocal Crosses between CitRUS CULTIVARS AND C. SCHWEINFURTHII. 'Nanpu' tangor, 'Chandler' pummelo [Citrus maxima (Burm.) Merr.], and C. schweinfurthii were used in the present study. The reciprocal crosses between two citrus cultivars and $C$. schweinfurthii were performed in the greenhouse. The cross combinations are shown in Table 1.

The flowers were pollinated immediately after emasculation and covered with paraffin paper bags. Seeds were collected from each fruit of all crosses at maturity and were classified into two groups (i.e., developed and undeveloped) according to their size and shape. After being numbered and weighed, both developed and undeveloped seeds were cultured on Murashige and Tucker (MT) medium (Murashige and Tucker, 1969) containing 500 $\mathrm{mg} \cdot \mathrm{L}^{-1}$ malt extract, $30 \mathrm{~g} \cdot \mathrm{L}^{-1}$ sucrose, and $2 \mathrm{~g} \cdot \mathrm{L}^{-1}$ gellan gum at $25{ }^{\circ} \mathrm{C}$ under continuous illumination $\left(38 \mu \mathrm{mol} \cdot \mathrm{m}^{-2} \cdot \mathrm{s}^{-1}\right)$. After germination, the seedlings were transplanted into vermiculite in pots and were transferred to a greenhouse.

\section{Confirmation of ploidy level}

FLOW CYTOMETRY. Young leaf segments of approximately 1 $\mathrm{cm}^{2}$ were collected from each of the seedlings and their parents, and chopped with a razor blade. These samples were treated for 5 min in $1 \mathrm{~mL}$ buffer solution containing $1.0 \%$ (v/v) Triton X-100 (Nacalai Tesque, Inc., Kyoto, Japan), 140 mm mercaptoethanol, $50 \mathrm{~mm} \mathrm{Na}_{2} \mathrm{SO}_{3}$, and $50 \mathrm{~mm}$ Tris- $\mathrm{HCl}$ at $\mathrm{pH} 7.5$, according to the preparation method of Yahata et al. (2005). Crude samples were filtered at $550 \mu \mathrm{L}$ through Miracloth (Merck KGaA, Darmstadt, Germany) and stained with $25 \mu \mathrm{g} \cdot \mathrm{L}^{-1}$ propidium iodide (PI). The relative fluorescence of the total DNA was measured for each nucleus with a flow cytometry system (EPICS XL; Beckman
Coulter, Fullerton, Calif.) equipped with an $\operatorname{argon}$ laser (488 nm, $15 \mathrm{~mW})$. The absolute nuclear genome size of the seedlings and their parents was estimated using nuclei of the tahiti lime (Citrus aurantifolia Swingle; $1.17 \mathrm{pg} / 2 \mathrm{C}, 2 \mathrm{n}=3 \mathrm{X}=27$ ) as an internal standard (Ollitrault et al., 1994).

Chromosome observation. Young leaves (approximately 3-5 mm long) were excised from all seedlings obtained from the reciprocal crosses between citrus cultivars and $C$. schweinfurthii, immersed in $2 \mathrm{~mm}$ 8-hydroxyquinoline for $10 \mathrm{~h}$ at $4{ }^{\circ} \mathrm{C}$ and fixed in a mixed solution of ethanol and acetic acid (3:1) for $12 \mathrm{~h}$ at 4 ${ }^{\circ} \mathrm{C}$. Enzymatic maceration and air-drying were performed according to the method of Fukui (1996) with some modifications. The young leaves were washed in distilled water to remove the fixative and then macerated in an enzyme mixture containing $2.0 \%(\mathrm{w} / \mathrm{v})$ Cellulase Onozuka RS (Yakult Pharmaceutical Industry Co., Ltd., Tokyo), $1.0 \%$ (w/v) Macerozyme R-200 (Yakult Pharmaceutical), $0.3 \%$ Pectolyase Y-23 (w/v) (Kyowa Chemical Products Co., Ltd., Osaka, Japan), and $200 \mathrm{~mm}$ EDTA at $37^{\circ} \mathrm{C}$ for $40 \mathrm{~min}$.

The chromosomes were stained with $2.0 \%$ Giemsa solution (Merck KGaA) in 1/30 phosphate buffer ( $\mathrm{pH} \mathrm{6.8)} \mathrm{for} 30 \mathrm{~min}$. Then, they were rinsed with distilled water, air dried, and observed under an optical microscope.

\section{Confirmation of hybridity}

Extraction of total DNA. Total DNA was extracted from young leaves of the seedlings and their parents according to the method of Doyle and Doyle (1987). The total DNA was used for analyses of the nuclear and cytoplasmic DNA by RAPD and CAPS

RAPD ANALYSIS OF NUCLEAR DNA. RAPD analysis of the nuclear DNA was performed by a modified method of Williams et al. (1990). For each combination of samples and primers, PCR was carried out twice, and only stable polymorphisms were analyzed.

CAPS ANALYSIS OF NUCLEAR AND CYTOPLASMIC DNA. The internal transcribed spacer (ITS) region in nuclear ribosomal RNA (rRNA) was used for nuclear DNA analysis. ITS 1 and ITS4 were used as primers (Yasui et al., 1998).

Amplification of $\mathrm{cp}$ - and mtDNA using $\mathrm{cp}$ - and mt universal primer pairs was performed in ASTEC Program Control System PC-700 (ASTEC Co., Fukuoka, Japan). For analysis of cpDNA, three primer pairs of rbcL-PSA I, TrnD-TrnT, and trnK-3914FtrnK-2R were used for amplification according to the methods of Cheng et al. (2003) and Ureshino and Miyajima (2002). For analysis of mtDNA, three primer pairs of $18 \mathrm{~S}$ rRNA-5S rRNA,

Table 1. Fruit set and seed contents in the reciprocal crosses between citrus cultivars and Citropsis schweinfurthii.

\begin{tabular}{|c|c|c|c|c|c|c|c|c|c|c|c|c|c|}
\hline \multicolumn{2}{|c|}{ Cross combination } & \multirow{2}{*}{$\begin{array}{c}\text { Flowers } \\
\text { pollinated } \\
\text { (no.) }\end{array}$} & \multirow{2}{*}{$\begin{array}{l}\text { Fruit } \\
\text { set } \\
\text { (no.) }\end{array}$} & \multirow{2}{*}{$\begin{array}{c}\text { Fruit } \\
\text { set } \\
(\%)\end{array}$} & \multirow{2}{*}{$\begin{array}{c}\text { Avg } \\
\text { fruit } \\
\text { wt } \\
(\mathrm{g})\end{array}$} & \multicolumn{4}{|c|}{ Seeds (no.) } & \multirow{2}{*}{$\begin{array}{c}\text { Dev. }^{z} \\
\text { seeds per } \\
\text { fruit } \\
\text { (no.) }\end{array}$} & \multicolumn{2}{|c|}{$\begin{array}{c}\text { Avg seed } \\
\text { wt }(\mathrm{g})\end{array}$} & \multirow{2}{*}{$\begin{array}{l}\text { Dev. } \\
\text { seeds } \\
(\%)^{x}\end{array}$} \\
\hline Seed parent & Pollen parent & & & & & Normal & Small & Total & Undev. & & Totaly & Dev. & \\
\hline 'Nanpu' tangor & Open pollination & --- & 10 & --- & 306.0 & 56 & 1 & 57 & 10 & 5.7 & 0.18 & 0.21 & 85.1 \\
\hline 'Nanpu' tangor & C. schweinfurthii & 70 & 28 & 40.0 & 273.0 & 1 & 42 & 43 & 7 & 1.5 & 0.02 & 0.02 & 86.0 \\
\hline 'Chandler' pummelo & Open pollination & --- & 3 & --- & 1484.0 & 272 & 7 & 279 & 15 & 93.0 & 0.37 & 0.39 & 94.9 \\
\hline 'Chandler' pummelo & C. schweinfurthii & 50 & 9 & 18.0 & 827.8 & 0 & 0 & 0 & 0 & --- & --- & --- & --- \\
\hline C. schweinfurthii & Open pollination & -- & --- & -- & --- & --- & --- & --- & --- & --- & --- & --- & --- \\
\hline C. schweinfurthii & 'Nanpu' tangor & 50 & 1 & 2.0 & 3.62 & 3 & 0 & 3 & 0 & 3.0 & 0.03 & 0.03 & 100 \\
\hline C. schweinfurthii & 'Chandler' pummelo & 50 & 6 & 12.0 & 4.38 & 9 & 0 & 9 & 2 & 1.5 & 0.05 & 0.05 & 81.8 \\
\hline
\end{tabular}

zDeveloped.

yNormal seed + small seed + undeveloped seed.

$\times($ Normal seed + small seed $/$ total seed $) \times 100$. 

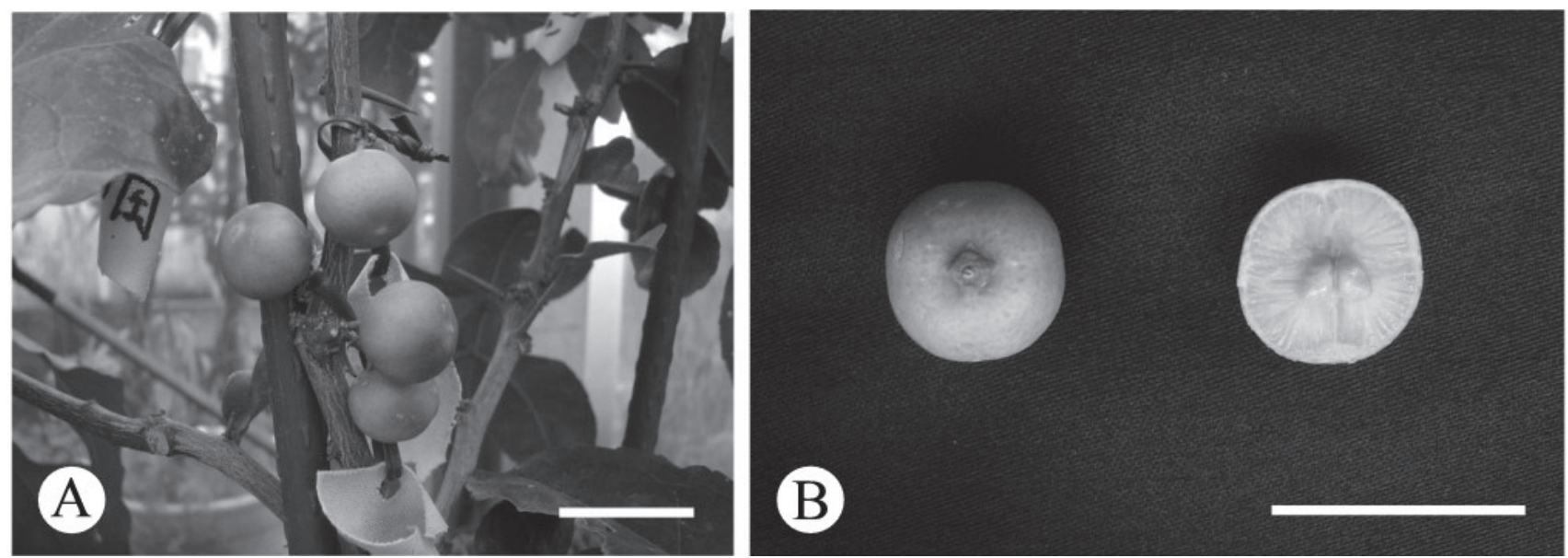

Fig. 1. The fruit obtained from the cross between Citropsis schweinfurthii and 'Nanpu' tangor $(\mathbf{A})$ and cross-section of their fruit $(\mathbf{B}) ;$ bars $=3 \mathrm{~cm}$.

nad 4 exon 1-nad 4 exon 2, and nad7/1-nad7/2r were used for amplification according to the method of Cheng et al. (2003) and Dumolin-Lapegue et al. (1997).

\section{Results and Discussion}

The reciprocal crosses between two citrus cultivars and $C$. schweinfurthii were carried out (Table 1). When C. schweinfurthii was used as the seed parent, three and nine developed seeds were obtained from crossing with 'Nanpu' tangor and 'Chandler' pummelo, respectively (Fig. 1). Conversely, when two monoembryonic citrus cultivars, 'Nanpu' tangor and 'Chandler' pummelo, were pollinated with pollen of $C$. schweinfurthii, fruit were set in both cross combinations. Although no seeds were obtained from the cross between 'Chandler' pummelo and C. schweinfurthii, 43 developed seeds and seven undeveloped seeds were obtained from fruit of 'Nanpu' tangor (Fig. 2). All of the developed seeds were very small, and their weight $(0.02 \mathrm{~g})$ was approximately $1 / 10$ that of the seeds obtained from open pollination in 'Nanpu' tangor $(0.21 \mathrm{~g})$ (Table 1$)$. Iwamasa et al. (1985) reported that when 'Miyauchi-Iyokan' (Citrus iyo hort. ex Tanaka) was pollinated with pollen of $C$. schweinfurthii, several undeveloped seeds were obtained. Similarly, in the present study, a lot of small seeds were obtained from the crosses between 'Nanpu' tangor and $C$. schweinfurthii.

The developed and undeveloped seeds obtained from the reciprocal crosses between 'Nanpu' tangor and C. schweinfurthii, and the cross between $C$. schweinfurthii and 'Chandler' pummelo were cultured on MT medium. Developed seeds obtained from the reciprocal crosses between 'Nanpu' tangor and C. schweinfurthii germinated normally. Conversely, in the cross between C. schweinfurthii and 'Chandler' pummelo, developed seeds of seven in nine plants did not germinate and the remaining seeds of two plants formed several embryoids. However, no plantlets were regenerated from these embryoids. Consequently, three and 28 seedlings were obtained from crosses between $C$. schweinfurthii and 'Nanpu' tangor and the reverse cross, respectively. After being transplanted to soil, these seedlings grew poorly and produced unifoliate leaves. However, when these seedlings were micrografted onto trifoliate orange [Poncirus trifoliata (L.) Raf.], they grew normally and had trifoliate winged leaves, showing the intermediate leaf characteristics of both parents (Fig. 3A). The morphology of these seedlings obtained in the present study was

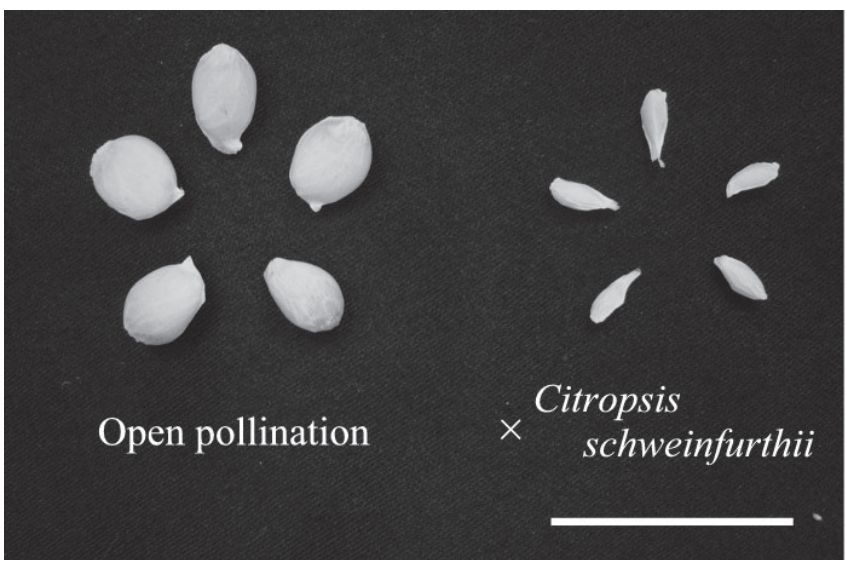

Fig. 2. Comparision of seed size obtained from open pollination and crossing with Citropsis schweinfurthii in 'Nanpu' tangor; bar $=3 \mathrm{~cm}$.

similar to that of the tetraploid somatic hybrids reported previously (Takami et al., 2005).

All seedlings were analyzed for ploidy level by flow cytometry analysis and chromosome observation. In flow cytometric analysis, the absolute nuclear genome size of $C$. schweinfurthii $(0.90 \mathrm{pg} / 2 \mathrm{C})$ was apparently different from that of 'Nanpu' tangor $(0.78 \mathrm{pg} / 2 \mathrm{C})$, which was equal to that of the other citrus cultivars. The absolute nuclear genome size of these seedlings $(\sim 0.84 \mathrm{pg} / 2 \mathrm{C})$ was the intermediate of those of 'Nanpu' tangor and C. schweinfurthii (Fig. 4). The chromosome count of the young leaves revealed that the chromosome number of these seedlings was $18(2 n=2 X=18)$ (Fig. 3B). Moreover, aneuploidy was not found among all the seedlings.

Although nuclear genome size in the diploid citrus cultivars was estimated to lie between 0.73 and $0.82 \mathrm{pg} / 2 \mathrm{C}$ (Ollitrault et al., 1994), C. schweinfurthii showed a significantly larger genome size. Iwamasa et al. (1988) reported that Citrus and Citropsis were sexually incompatible. However, the results reported herein prove that there is limited sexual compatibility between Citrus and Citropsis. One possible cause for the limited sexual compatibility could be the difference in their chromosome structure. The difference of genome size between Citrus and Citropsis shown in the present study might be the possible reason for their limited sexual compatibility. 

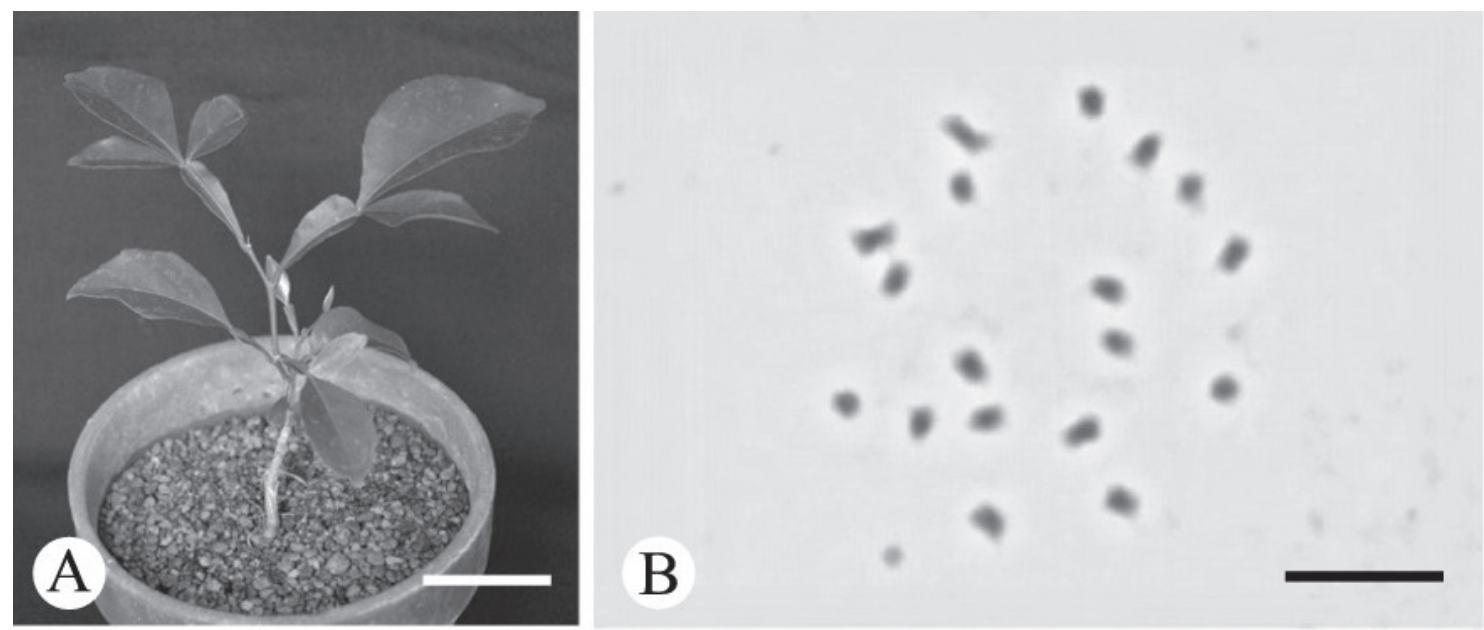

Fig. 3. The seedling obtained from the cross between Citropsis schweinfurthii and 'Nanpu' tangor $(\mathbf{A})(\mathrm{bar}=3 \mathrm{~cm})$ and its metaphase chromosomes in young leaves (B) $(2 \mathrm{n}=2 \mathrm{X}=18 ; \mathrm{bar}=10 \mu \mathrm{m})$.

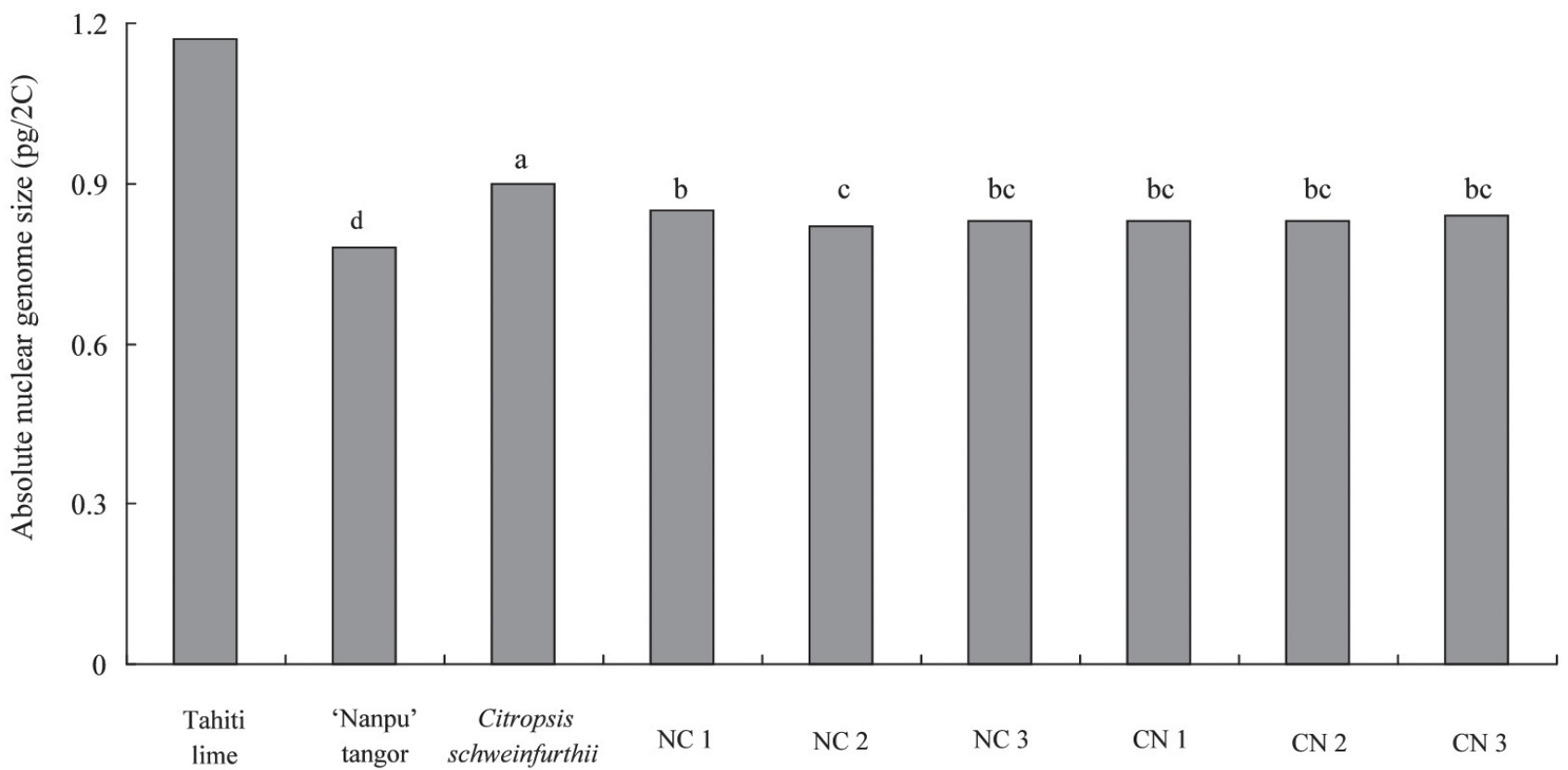

Fig. 4. Nuclear genome size of 'Nanpu' tangor, Citropsis schweinfurthii, and the seedlings obtained from the reciprocal crosses between 'Nanpu' tangor and $C$. schweinfurthii determined by the comparison with the tahiti lime as an internal standard. NC1, NC2, NC3 = seedlings obtained from the cross between 'Nanpu' tangor and C. schweinfurthii; $\mathrm{CN} 1, \mathrm{CN} 2, \mathrm{CN} 3$ = seedlings obtained from the cross between $C$. schweinfurthii and 'Nanpu' tangor. Different letters represent significant differences in Tukey's multiple range test, $1 \%$ level. Nuclear genome size of the sample was estimated using nuclei of the tahiti lime [1.17 pg of DNA content per somatic nucleus (2C), $2 \mathrm{n}=3 \mathrm{X}=27$ ] as an internal standard (Ollitrault et al., 1994).

To confirm the hybridity of these seedlings, we employed RAPD analysis for six seedlings (NC1, NC2, and NC3 obtained from the cross between 'Nanpu' tangor and C. schweinfurthii, and $\mathrm{CN} 1, \mathrm{CN} 2$, and $\mathrm{CN} 3$ obtained from the reverse cross) and both parents. As shown in Fig. 5, these seedlings yielded bands specific to both parents. Hybridity of these seedlings was further confirmed using CAPS. Amplification of the ITS region of nuclear DNA resulted in a fragment of the same size for these seedlings and both parents. After digestion of the fragment with Sma I, these seedlings had specific bands derived from both parents (Fig. 6). $\mathrm{Cp}$ - and mtDNA amplifications were also performed on these seedlings and both of their parents using three cp- and mtDNA universal primer pairs. While every primer pair amplified the bands satisfactorily, they did not reveal any polymorphism on the agarose gels. When the PCR products were digested with four restriction endonucleases, cpDNA polymorphism was observed in four primer/enzyme combinations as follows: rbcL-PSA I / Msp I (Fig. 7), TrnD-TrnT / Mbo I and Msp I, and trnK-3914F-trnK-2R / Hae III. MtDNA polymorphism was seen in a primer / enzyme combination of nad7/1-nad7/2r / Alu I (Fig. 8). These seedlings had uniform and identical bands to those of the seed parents. This result indicated that cytoplasmic DNA of these seedlings was of 
OPC-2

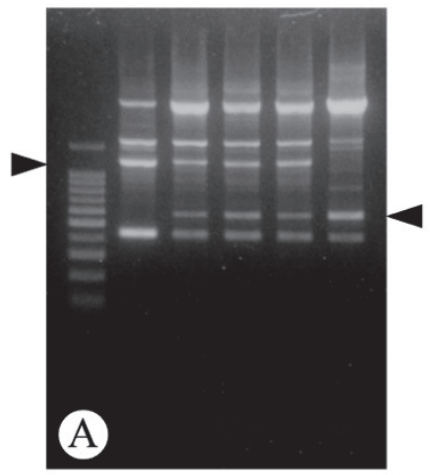

M N NC1 NC2 NC3 C
OPH-7

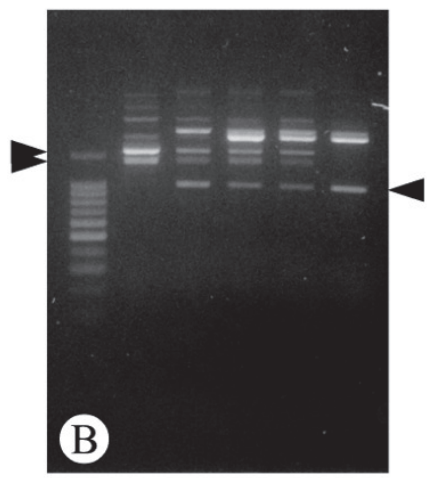

M C CN1 CN2 CN3 N

Fig. 5. RAPD analysis of the seedlings obtained from the reciprocal crosses between 'Nanpu' tangor and Citropsis schweinfurthii. (A) Cross between 'Nanpu' tangor and C. schweinfurthii. (B) Cross between $C$. schweinfurthii and 'Nanpu' tangor. Arrows indicate the bands specific to each parent. $\mathrm{M}=$ 100-bp ladder marker; $\mathrm{N}=$ 'Nanpu' tangor; $\mathrm{C}=$ C. schweinfurthii; $\mathrm{NC} 1, \mathrm{NC} 2$, NC3 = seedlings obtained from the cross between 'Nanpu' tangor and $C$. schweinfurthii; CN1, CN2, CN3 = seedlings obtained from the cross between C. schweinfurthii and 'Nanpu' tangor.

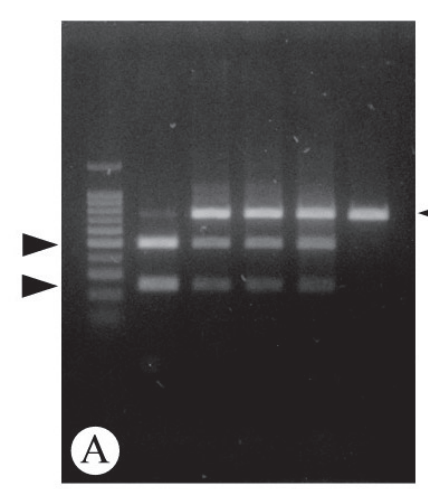

M N NC1 NC2 NC3 C

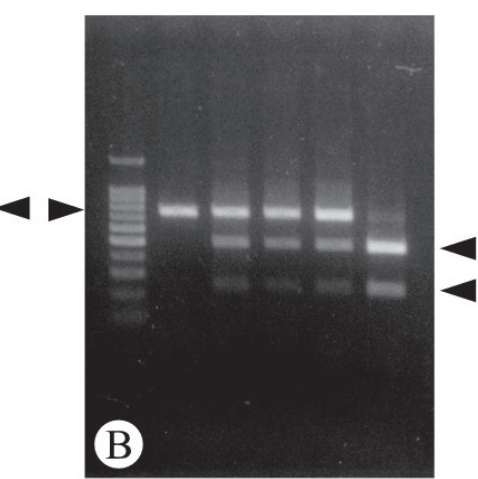

M C CN1 CN2 CN3 N

Fig. 6. Restriction pattern of the Sma I-digested ribosomal RNA (rRNA) internal transcribed spacer(ITS) of nuclear genomes. (A) Cross between 'Nanpu' tangor and C. schweinfurthii. (B) Cross between C. schweinfurthii and 'Nanpu' tangor. Arrows indicate the bands specific to each parent. $M=100$-bp ladder marker; $\mathrm{N}=$ 'Nanpu' tangor; $\mathrm{C}=C$. schweinfurthii; $\mathrm{NC} 1, \mathrm{NC} 2, \mathrm{NC} 3=$ seedlings obtained from the cross between 'Nanpu' tangor and C. schweinfurthii; CN1, $\mathrm{CN} 2, \mathrm{CN} 3$ = seedlings obtained from the cross between $C$. schweinfurthii and 'Nanpu' tangor.

maternal origin. Thus, RAPD and CAPS analyses confirmed that these seedlings were intergeneric sexual hybrids between Citrus and Citropsis.

Although production of the intergeneric hybrids between Citrus and Citropsis has been attempted many times to clarify their relationship (Barrett, 1977; Iwamasa et al., 1985, 1988), hybrid seedlings have never been obtained. Barrett (1977) obtained developed seeds from the cross of Citropsis with Citrus, whereas Iwamasa et al. (1988) obtained several developed and undeveloped seeds from the fruit of some monoembryonic citrus cultivars when they were pollinated with pollen of Citropsis. However, these seeds completely failed to germinate. Iwamasa et al. (1985) presumed that failure to germinate was caused by hypoplasia of the embryo by an unbalance of development between

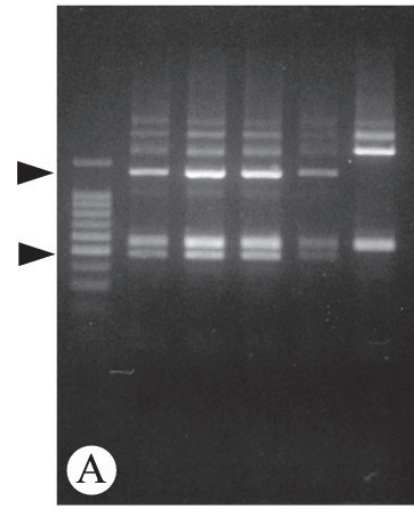

$\begin{array}{llllll}\mathrm{M} & \mathrm{N} & \mathrm{N} 1 & \mathrm{NC} & \mathrm{NC} & \mathrm{C}\end{array}$

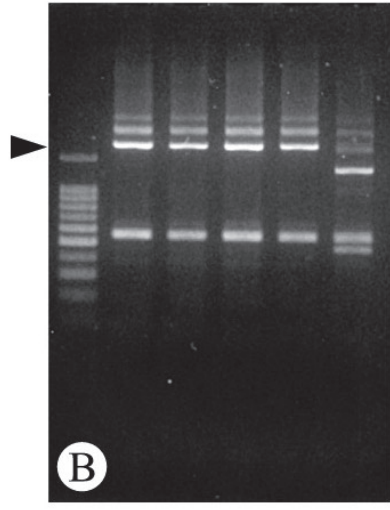

M C CN1 CN2 CN3 N
Fig. 7. Restriction pattern of the Msp I-digested rbcL-PSA I regions of chloroplast genomes. (A) Cross between 'Nanpu' tangor and C. schweinfurthii. (B) Cross between $C$. schweinfurthii and 'Nanpu' tangor. Arrows indicate the bands specific to each parent. $\mathrm{M}=100$-bp ladder marker; $\mathrm{N}=$ 'Nanpu' tangor; $\mathrm{C}=C$. schweinfurthii; $\mathrm{NC} 1, \mathrm{NC} 2, \mathrm{NC} 3$ = seedlings obtained from the cross between 'Nanpu' tangor and C. schweinfurthii; $\mathrm{CN} 1, \mathrm{CN} 2, \mathrm{CN} 3$ = seedlings obtained from the cross between $C$. schweinfurthii and 'Nanpu' tangor.

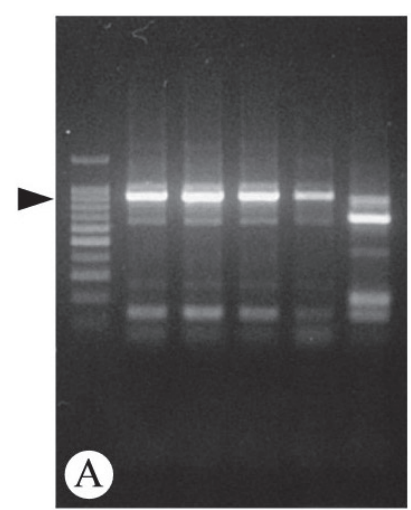

M N NC1 NC2 NC3 C

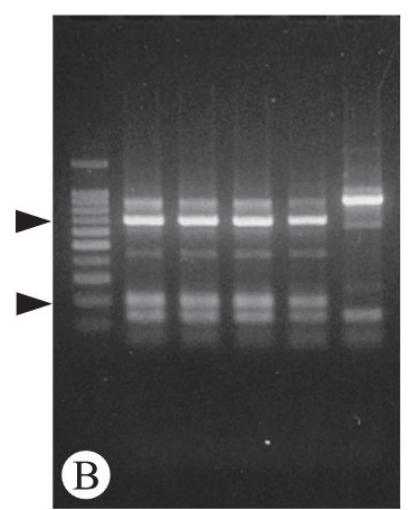

M C CN1 CN2 CN3 N
Fig. 8. Restriction pattern of the Alu I-digested nad7/1-nad7/2r regions of mitochondrial genomes. (A) Cross between 'Nanpu' tangor and C. schweinfurthii. (B) Cross between C. schweinfurthii and 'Nanpu' tangor. Arrows indicate the bands specific to each parent. $\mathrm{M}=100$-bp ladder marker; $\mathrm{N}=$ 'Nanpu' tangor; $\mathrm{C}=C$. schweinfurthii; $\mathrm{NC} 1, \mathrm{NC} 2, \mathrm{NC} 3$ = seedlings obtained from the cross between 'Nanpu' tangor and $C$. schweinfurthii; CN1, CN2, CN3 = seedlings obtained from the cross between $C$. schweinfurthii and 'Nanpu' tangor.

the embryo and endosperm, and they suggested the necessity of embryo culture to produce the intergeneric hybrids between Citrus and Citropsis. In the present study, we tried in vitro culture for all the seeds obtained from the reciprocal crosses between citrus cultivars and $C$. schweinfurthii on MT medium. Consequently, most of the developed seeds germinated normally, and hybrid seedlings were obtained.

In conclusion, several intergeneric hybrid seedlings between Citrus and Citropsis were produced in the present study. In the future, studies of meiosis and the fertility of these hybrids may yield additional information on chromosome affinity that may prove useful in determining the phylogenetic relationship between Citrus and Citropsis. Therefore, these sexual hybrid seedlings could be useful material for clarifying the origin of Citrus. 


\section{Literature Cited}

Barrett, H.C. 1977. Integeneric hybridization of Citrus and other genera in citrus cultivar improvement. Proc. Intl. Soc. Citricult. 2:586-589.

Cheng, Y.J., W.W. Guo, and X.X. Deng. 2003. Molecular characterization of cytoplasmic and nuclear genomes in phenotypically abnormal Valencia orange (Citrus sinensis) + Meiwa kumquat (Fortunella crassifolia) intergeneric somatic hybrids. Plant Cell Rpt. 21:445-451.

Doyle, J. and J.L. Doyle. 1987. A rapid DNA isolation procedure for small quantities fresh leaf tissue. Phytochem. Bul. 19:11-15.

Dumolin-Lapegue, S., M.H. Pemonge, and R.J. Petit. 1997. An enlarged set of consensus primers for the study of organelle DNA in plants. Mol. Ecol. 6:393-397.

Federici, C.T., D.O. Fang, R.W. Scorza, and M.L. Roose. 1998. Phylogenetic relationships within the genus Citrus (Rutaceae) and related genera as revealed by RFLP and RAPD analysis. Theor. Appl. Genet. 96:812-822.

Fukui, K. 1996. Plant chromosome at mitosis, p. 1-17. In: K. Fukui and S. Nakayama (eds.). Plant chromosome. Laboratory methods. CRC Press, Boca Raton, Fla.

Green, R.M., A. Vardi, and E. Galun. 1986. The plastome of Citrus. Physical map, variation among Citrus cultivars and species and comparison with related genera. Theor. Appl. Genet. 72:170-177.

Grosser, J.W., F.A.A. Mourao-Fo, F.G. Gmitter, Jr., E.S. Louzada, J. Jiang, K. Baergen, A. Ouiros, C. Cabasson, J.L. Schell, and J.L. Chandler. 1996. Allotetraploid hybrids between Citrus and seven related genera produced by somatic hybridization. Theor. Appl. Genet. 92:577-582.

Grosser, J.W. and F.G. Gmitter, Jr. 1990. Somatic hybridization of Citrus with wild relatives for germplasm enhancement and cultivar development. HortScience 25:147-151.

Grosser, J.W., F.G. Gmitter, Jr., N. Tusa, and J.L. Chandler. 1990. Somatic hybrid plants from sexually incompatible woody species: Citrus reticulata and Citropsis gilletiana. Plant Cell Rpt. 8:656-659.

Hirai, M. and I. Kajiura. 1987. Genetic analysis of leaf isozymes in Citrus. Jpn. J. Breeding 37:377-388.

Hirai, M., I. Kozaki, and I. Kajiura. 1986. Isozyme analysis and phylogenic relationship of Citrus. Jpn. J. Breeding 36:377-389.

Iwamasa, M., N. Nito, and J.T. Ling. 1988. Intra- and intergeneric hybridization in the orange subfamily, Aurantioideae, p. 123-130. In: R. Goren and K. Mendel (eds.). Proc. Sixth Intl. Citrus Congr. Margraf Scientific Books, Weikersheim, Israel.

Iwamasa, M., N. Nito, Y. Katayama, T. Yamaguchi, and S. Matsunaga.
1985. Cross-compatibility between Aurantioideae plants. Bul. Faculty Agr. Saga Univ. 59:57-69 (In Japanese with English summary).

Ling, J.T. and M. Iwamasa. 1994. Somatic hybridization between Citrus reticulata and Citropsis gabunensis through electrofusion. Plant Cell Rpt. 13:493-497.

Murashige, T. and D.P.H. Tucker. 1969. Growth factor requirement of citrus tissue culture. p.1155-1161. In: H.D. Chapmam (ed.). Proc. First Intl. Citrus Symp. Vol. 3. University of California, Riverside.

Nicolosi, E., Z.N. Deng, A. Gentile, S.L. Malfa, G. Continella, and E. Tribulato. 2000. Citrus phylogeny and genetic origin of important species as investigated by molecular markers. Theor. Appl. Genet. 100:1155-1166.

Ollitrault, P., D. Dambier, F. Luro, and C. Duperray. 1994. Nuclear genome size variations in Citrus. Fruits 49:390-393.

Swingle, W.T. and P.C. Reece. 1967. The botany of Citrus and its wild relatives, p. 190-430. In: W. Reuther, H.J. Weber, and L.D. Batchelor (eds.). The Citrus industry, Vol. I, History, world distribution, botany and varieties. University of California Press, Berkeley.

Takami, K., A. Matsumaru, M. Yahata, H. Kunitake, and H. Komatsu. 2005. Utilization of intergeneric somatic hybrids as an index discriminating taxa in the genus Citrus and its related species. Sexual Plant Reproduction 18:21-28.

Tanaka, T. 1977. Fundamental discussion of Citrus classification. Studia Citorologica 14:1-6.

Ureshino, K. and I. Miyajima. 2002. The study on the relationship between leaf colors and ptDNA inheritance in intersectional cross of Rhododendron kiusianum $\mathrm{x}$ R. japonicum $\mathrm{f}$. flavum, resulting in an unexpected triploid progeny. J. Jpn. Soc. Hort. Sci. 71:214-219.

Williams, J.G.K., A.R. Kubelik, K.J. Lival, J.A. Rafalski, and S. V. Tingey. 1990. DNA polymorphisms amplified by arbitrary primers are useful as genetic markers. Nucleic Acids Res. 18:6531-6535.

Yahata, M., S. Harusaki, H. Komatsu, K. Takami, H. Kunitake, T. Yabuya, K. Yamashita, and P. Toolapong. 2005. Morphological characterization and molecular verification of a fertile haploid pummelo (Citrus grandis Osbeck). J. Amer. Soc. Hort. Sci. 130:34-40.

Yamamoto, M. and S. Kobayashi. 1996. Polymorphism of chloroplast DNA in citrus. J. Jpn. Soc. Hort. Sci. 65:291-296.

Yamamoto, M., S. Kobayashi, Y. Nakamura, and Y. Yamada. 1993. Phylogenic relationships of citrus revealed by RFLP analysis of mitochondrial and chloroplast DNA. Jpn. J. Breeding 43:355-365.

Yasui, Y. and O. Ohnishi. 1998. Phylogenetic relationships among Fagopyrum species revealed by the nucleotide sequences of the ITS region of the nuclear rRNA gene. Genes Genet. Systems 73:201-210. 